\title{
Retrieval-induced forgetting and part-list cuing in associatively structured lists
}

\author{
KARL-HEINZ BÄUML and CHRISTOF KUHBANDNER \\ Regensburg University, Regensburg, Germany
}

\begin{abstract}
Using DRM lists (Roediger \& McDermott, 1995) in two experiments, we compared the effects of retrieval practice on a subset of the items and of the presentation of those items as retrieval cues at test on recall of the lists' critical items. In Experiment 1, the critical items were part of the studied lists, thus addressing these items' veridical recall; in Experiment 2, they were not studied, thus addressing these items' false recall. Three major results emerged. First, retrieval practice and part-list cuing reduced both veridical and false recall. Second, the two manipulations induced an integration effect in veridical recall, with substantial forgetting in lists with low false recall levels and no forgetting in lists with high false recall levels. Third, retrieval practice and part-list cuing created the same effects on recall, qualitatively and quantitatively. These results suggest that the detrimental effects of retrieval practice and part-list cuing were mediated by similar mechanisms. They are consistent with the view that not only retrieval-induced forgetting, but also part-list cuing is caused by inhibitory processes.
\end{abstract}

The presence of adequate retrieval cues is crucial for successful episodic recall (e.g., Tulving, 1974). This knowledge is reflected both in computational models of episodic memory (Raaijmakers \& Shiffrin, 1981) and in interrogation techniques such as the cognitive interview (Geiselman, Fisher, MacKinnon, \& Holland, 1985). Indeed, cuing has been found to facilitate recall in many situations. For instance, if a categorized item list with several items from each category is presented to participants and, at test, the category names or one item from each category are provided as retrieval cues, such cuing typically enhances recall performance, as compared with unaided free recall (Tulving \& Pearlstone, 1966).

Cuing, however, is not always facilitatory. If participants learn a categorized item list and, at test, receive several items from each category as a retrieval cue, such part-list cuing often reduces recall performance for the remaining items, as compared with the condition in which just one category exemplar is provided as a retrieval cue (Roediger, 1973; Slamecka, 1968). In general, if more part-list cues are provided than is necessary to remind participants of the various categories, or subjective units, cuing can be detrimental. The detrimental effect of part-list cuing has been found to be fairly robust, occurring with both categorized and uncategorized lists and with either intralist or extralist items as cues (see Nickerson, 1984, for a review).

The research reported here was presented at the 3rd International Conference on Memory (ICOM'3; July 2001, Valencia). It was supported by Grant Ba-1382/4 from the Deutsche Forschungsgemeinschaft to K.-H.B. We thank M. Meier and M. Zellner for their assistance in the experimental work. We also thank P. Foos, B. Basden, and M. Anderson for comments on an earlier version of the manuscript. Correspondence should be addressed to K.-H. Bäuml, Department of Experimental Psychology, Regensburg University, 93040 Regensburg, Germany (e-mail: karl-heinz.baeuml@psychologie.uni-regensburg.de).
In a similar manner, retrieval can induce forgetting. Suppose participants are presented a categorized item list with several items from each category and, subsequently, retrieve half of the items from each category, given partial word stems of these items as retrieval cues. Such retrieval practice typically improves later recall of the practiced items. At the same time, however, it often impairs recall of the nonpracticed items, relative to a condition in which there is no such retrieval practice (Anderson, R. A. Bjork, \& E. L. Bjork, 1994; Anderson \& Spellman, 1995). Like part-list cuing, retrieval-induced forgetting has been found to be fairly robust and to occur with both intralist retrieval practice and the generation of semantically related extralist items (see Levy \& Anderson, 2002, for a review). Retrievalinduced forgetting also appears to underlie the well-known output interference effect (Bäuml \& Hartinger, 2002), which describes the decline in an item's recall probability as a function of its occupying a progressively later serial position in a testing sequence (Roediger \& Schmidt, 1980; A. D. Smith, 1971).

\section{Theoretical Accounts of the \\ Detrimental Effects of Retrieval and Cuing}

Part-list cuing and retrieval-induced forgetting were originally proposed to be mediated by the same mechanism and were explained in terms of strength-dependent competition (Rundus, 1973). According to this principle, part-list cuing and retrieval practice strengthen the cue items and practiced items and make these items stronger competitors for the noncue and nonpracticed items. Due to the increased competition, recall for the noncue and nonpracticed items gets harder, and as a result, forgetting arises.

Since then, the competition principle has been found to be inadequate to account for retrieval-induced forgetting. It was demonstrated that, whereas the repeated retrieval of 
material can cause forgetting of related material, the repeated presentation of material does not, thus indicating that retrieval-induced forgetting is not due to the strengthening of the practiced items (Anderson, E. L. Bjork, \& R. A. Bjork, 2000; Bäuml, 1997, 2002; Ciranni \& Shimamura, 1999). Recent accounts of retrieval-induced forgetting, instead, have been based on inhibition (Anderson et al., 1994; Anderson \& Spellman, 1995). This view rests on the assumption that items that share a common cue compete for conscious recall if that cue is provided. If one of the items then is practiced, the other items sharing the same cue are assumed to interfere and, to guarantee a successful recovery of the to-be-practiced item, need to be inhibited. Because items strongly associated to the common cue are supposed to induce more interference than items weakly associated to that cue, they should be subject to more inhibition than are the weakly associated items. In agreement with this account, retrieval-induced forgetting was found to be larger for high-frequency than for lowfrequency members of categories (Anderson et al., 1994; Bäuml, 1998; but see Butler, Williams, Maki, \& Zacks, 2001, for a failure to show this effect, and MacLeod, Dodd, Sheard, Wilson, \& Bibi, 2003, for theoretical alternatives).

The competition principle is still regarded by some as an adequate explanation of part-list cuing (Kimball \& Bjork, 2002). Recently, however, two alternative accounts have been suggested. One is strategy disruption. According to this hypothesis (D. R. Basden \& B. H. Basden, 1995; D. R. Basden, B. H. Basden, \& Galloway, 1977), the presentation of cue items disrupts retrieval by forcing a serial recall order that is inconsistent with the subjective organization of the list. In agreement with this view, smaller recall impairments were reported if the presentation of cue items was consistent with participants' preferred recall order than if it was strategy inconsistent (D. R. Basden \& B. H. Basden, 1995; Sloman, Bower, \& Rohrer, 1991). Following this line of reasoning, part-list cuing induces a change in the retrieval process from a more effective one when cues are absent to a less effective one when they are present (see Raaijmakers \& Shiffrin, 1981, and Sloman et al., 1991, for related suggestions). Retrieval-induced forgetting and part-list cuing thus should be mediated by quite different mechanisms.

The other account arises from considering that part-list cuing often causes participants to retrieve the cue items before the noncue items. Cue items may be retrieved before noncue items either overtly, if both noncue and cue items are to be recalled (Roediger, Stellon, \& Tulving, 1977), or covertly during attempts to recall the noncue items. In each case, retrieval of the cue items may impair noncue item recall by causing retrieval-induced inhibition of the noncue items (Anderson et al., 1994, p. 1081). Following this account, not only retrieval-induced forgetting, but also partlist cuing should be caused by inhibitory processes. This explanation of part-list cuing is consistent with the results from recent work, in which several parallels between the two forms of forgetting have been found (Bäuml, 2002; Hicks \& Starns, in press). One of these parallels is that, like retrieval-induced forgetting, part-list cuing is larger for high-frequency than for low-frequency members of categories (Bäuml, Kissler, \& Rak, 2002), a finding that agrees with the inhibition view of part-list cuing.

\section{Boundary Conditions of Retrieval-Induced Forgetting}

By considering the boundary conditions of retrievalinduced forgetting and examining such conditions in partlist cuing, we can learn more about the extent to which the two forms of forgetting are mediated by different, or similar, mechanisms. In experiments on retrieval-induced forgetting, it has been shown that the forgetting can be greatly reduced or even eliminated if participants form interconnections between competing memories, a process called integration. Anderson and McCulloch (1999), for instance, found that encouraging participants to interrelate the exemplars of studied categories during the study phase largely reduced retrieval-induced forgetting. Consistently, postexperimental questionnaires indicated that even when people were not instructed to interrelate exemplars, they often did so spontaneously and that this spontaneous integration also reduced the forgetting. In a study of the fan effect, Radvansky (1999) found a similar pattern of less forgetting when participants integrated propositional knowledge into what he called location schemas. By integrating facts into more cohesive representations, participants appear to experience less interference between related facts, require less inhibition, and thus are protected from impairment (Anderson \& Bell, 2001; E. E. Smith, Adams, \& Schorr, 1978; but see R. E. Smith \& Hunt, 2000, for conflicting results).

In agreement with the integration findings, retrievalinduced forgetting can also be reduced or eliminated if there is a high degree of similarity between practiced and nonpracticed items, caused either by instructed relational processing of the two types of items (Anderson, Green, \& McCulloch, 2000) or by a strong categorial relation between them (Bäuml \& Hartinger, 2002). Bäuml and Hartinger, for instance, let participants study categorized item lists, with each category consisting of exemplars from two different semantic subcategories. They found that the retrieval of a subset of the studied items impaired the subsequent recall of the nonpracticed items if the two types of items were relatively dissimilar to each other (i.e., belonged to the same category, but to a different subcategory) but did not induce impairment if the two types of items were highly similar (i.e., belonged to the same category and subcategory). Such effects of integration and item similarity are consistent with the feature inhibition view of retrievalinduced forgetting (Anderson \& Spellman, 1995). They have not yet been examined in part-list cuing.

\section{DRM Item Lists}

Deese-Roediger-McDermott (DRM) item lists (Deese, 1959; Roediger \& McDermott, 1995) consist of items that are all strongly associated to a so-called critical item. When presented to participants, such lists can create high levels of false recall of the unstudied critical item. For in- 
stance, if participants study such words as pillow, bed, silence, and so forth, all of which are the strongest semantic associates to the unpresented critical item, sleep, they are highly likely to recall the critical item falsely. Moreover, for falsely recalled critical items, participants typically report that they remember experiencing some phenomenon in connection with the item's presentation, as opposed to merely knowing that the item had been presented (Read, 1996; Roediger \& McDermott, 1995). DRM lists are important because they are markedly successful in creating robust false memories (see Roediger, McDermott, \& Robinson, 1998, for a review). Due to their unique associative structure, they can also be useful for studying other memory phenomena, such as the effects of retrieval practice and part-list cuing.

The high degree of associative strength between the critical item and the noncritical items in DRM lists indicates that the critical item and the noncritical ones are strongly interlinked with one another. Due to this integration, the retrieval of the noncritical items should cause little cost for the subsequent recall of the critical item and, therefore, induce little retrieval-induced forgetting. Moreover, DRM lists differ substantially in the degree to which they cause false memories (Stadler, Roediger, \& McDermott, 1999). As the results of regression analyses have shown (Roediger, Watson, McDermott, \& Gallo, 2001), this variation in false-recall level is largely due to differences in the associative strength between the lists' critical item and the noncritical ones. In fact, the degree to which the noncritical items evoke associations to the critical item nicely predicts false recall (see also McEvoy, Nelson, \& Komatsu, 1999). Following these results, high false-recall levels indicate a higher degree of interconnections between the noncritical items and the critical one, and low false-recall levels indicate a lower degree. Thus, on the basis of the integration findings, more retrieval-induced forgetting should arise for low false-recall lists than for high false-recall lists, with the latter showing hardly any forgetting at all.

Predictions about the effects of part-list cuing in DRM lists depend on the particular theoretical account. Following the inhibition account of part-list cuing, of course, the same predictions arise for the effects of part-list cuing as for the effects of retrieval practice. Thus, critical items in DRM lists should show little forgetting, particularly in high false-recall lists. Following the strategy disruption account, however, the opposite prediction arises: The critical items should be quite vulnerable to the effects of part-list cuing, particularly in high false-recall lists. Indeed, according to strategy disruption, people adopt retrieval strategies, thereby using a variety of techniques to organize their recall-among them, interitem associations (B. H. Basden, D. R. Basden, \& Stephens, 2002; D. R. Basden, 1973). The stronger the interitem associations, the higher the degree of organization and, thus, the greater the susceptibility to strategy disruption (Anderson \& McCulloch, 1999). Therefore, in high false-recall lists with their high degree of integration, part-list cuing should induce more forget- ting of critical items than in low false-recall lists, with their relatively low degree of integration. The predictions of the disruption view thus contrast sharply with the predictions of the inhibition view.

\section{EXPERIMENT 1}

Integration has been shown to reduce retrieval-induced forgetting. In Experiment 1, we examined whether this finding would generalize to DRM lists with high and low false-recall levels. More important, we examined whether integration would have the same or a different effect in part-list cuing versus retrieval-induced forgetting. If integration reduced forgetting as a result of retrieval practice but increased forgetting as a result of part-list cuing, such a finding would establish an important dissociation between partlist cuing and retrieval practice, indicating that the two forms of forgetting are mediated by quite different mechanisms. However, if integration affected retrieval-induced forgetting and part-list cuing in the same manner, such a result would be consistent with the view that retrievalinduced forgetting and part-list cuing are mediated by similar mechanisms. In this case, inhibition might be the responsible mechanism.

DRM lists have primarily been used to demonstrate false memory effects, rather than effects on the critical items' veridical recall (see Roediger et al., 2001). In Experiment 1, we nonetheless included the critical items in the study lists, because we expected such an inclusion to enhance effects of integration between the critical items and the noncritical ones. The participants were presented DRM lists and recalled the lists under three conditions: (1) a free-recall condition, which served as the control condition, (2) a part-list cuing condition, in which a subset of the noncritical items was provided as a retrieval cue at test, and (3) a retrieval practice condition, in which retrieval of a subset of the noncritical items was practiced before there was a free recall of all the list items. There was also a fourth experimental condition, in which the critical items were not part of the studied lists and a free-recall test was conducted. This condition was included to replicate the false-recall levels known from previous studies and, more important, to create an empirical basis for the distinction between high and low false-recall lists. On the basis of this distinction, we examined the extent to which the effects of retrieval practice and part-list cuing differed for the two types of lists and whether they showed, or did not show, an integration effect, in the sense that high false-recall lists show less forgetting than did low false-recall lists.

\section{Method}

Participants. Fifty-six psychology students at the University of Regensburg participated in the experiment. They were tested individually.

Materials. Sixteen item lists were drawn from the set of DRM lists reported by Stadler et al. (1999). They were chosen from those 20 lists that, according to the Stadler et al. norms, induce the highest false-recall levels. The first 14 items from each list were selected. These items are called the noncritical list items in the following, thus 
Table 1

Mean Percentages of Recall and Standard Errors as a Function of Recall Condition (Retrieval Practice/Part-List Cuing/Control) and Item Type (Critical/Noncritical) in Experiments 1 and 2

\begin{tabular}{|c|c|c|c|c|c|c|c|c|c|c|c|c|}
\hline \multirow[b]{3}{*}{ Item Type } & \multicolumn{6}{|c|}{ Experiment 1} & \multicolumn{6}{|c|}{ Experiment 2} \\
\hline & \multicolumn{2}{|c|}{$\begin{array}{c}\text { Retrieval } \\
\text { Practice }\end{array}$} & \multicolumn{2}{|c|}{$\begin{array}{c}\text { Part-list } \\
\text { Cuing }\end{array}$} & \multicolumn{2}{|c|}{$\begin{array}{c}\text { Control } \\
\text { Condition } \\
\end{array}$} & \multicolumn{2}{|c|}{$\begin{array}{l}\text { Retrieval } \\
\text { Practice }\end{array}$} & \multicolumn{2}{|c|}{$\begin{array}{c}\text { Part-list } \\
\text { Cuing }\end{array}$} & \multicolumn{2}{|c|}{$\begin{array}{c}\text { Control } \\
\text { Condition } \\
\end{array}$} \\
\hline & $M$ & $S E$ & $M$ & $S E$ & $M$ & $S E$ & $M$ & $S E$ & $M$ & $S E$ & $M$ & $S E$ \\
\hline Noncritical & 55.6 & 1.8 & 58.5 & 1.5 & 63.9 & 1.8 & 50.3 & 1.5 & 53.4 & 1.6 & 59.7 & 1.4 \\
\hline Critical & 74.5 & 2.7 & 72.8 & 2.8 & 88.8 & 2.2 & 27.9 & 2.9 & 23.3 & 3.4 & 35.8 & 3.0 \\
\hline Critical-HFR & 87.2 & 3.4 & 81.4 & 4.3 & 88.6 & 3.7 & 35.6 & 4.3 & 31.3 & 4.3 & 49.9 & 4.2 \\
\hline Critical-LFR & 65.5 & 4.4 & 67.0 & 4.8 & 86.2 & 3.6 & 19.6 & 3.8 & 15.9 & 3.8 & 20.2 & 3.3 \\
\hline
\end{tabular}

Note-In Experiment 1, both the noncritical items and the critical items were part of the studied lists; critical item recall thus reflects veridical recall. In Experiment 2, only the noncritical items were part of the studied lists; critical item recall thus reflects false recall. Critical-HFR, critical item recall in the high false-recall set of lists, consisting of the eight DRM lists with the highest false-recall levels; CriticalLFR, critical item recall in the low false-recall set of lists, consisting of the eight (Experiment 1) or seven (Experiment 2) DRM lists with the lowest false-recall levels.

contrasting them with a list's so-called critical item. The critical and noncritical items were translated into German. In some cases, this translation offers some degree of freedom. This freedom was used to create lists in which the first seven associates to the critical itemthat is, a list's first seven items in the Stadler et al. norms-had two unique initial letters with respect to their list. Thus, the uniqueness of a cue consisting of the items' two initial letters was guaranteed.

Design. There were four experimental conditions in this experiment. In all four conditions, DRM lists consisting of 14 items each were presented to the participants. In one condition, referred to as the false-memory condition, all 14 selected noncritical items of a DRM list were presented, and participants later had to freely recall as many of the presented items as possible. In the other three conditions, only the first 13 of the 14 selected noncritical items of a DRM list were presented; in addition, the critical item was included in the list. These three experimental conditions differed in recall conditions only. In the part-list cuing condition, a list's first seven associates to the critical item were presented as retrieval cues. The participants were instructed to read these items aloud and to try to use them as cues to recall as many of the remaining items as possible. In the retrieval practice condition, the participants engaged in a twostage recall test. In the first stage, they had to recall a list's first seven associates to the critical item, given the two unique initial letters of these items as a retrieval cue; then, in the second stage, they had to freely recall as many of the list items as possible. This two-stage procedure mimics the one used in Anderson et al.'s (1994) retrieval practice paradigm. Finally, there was a control condition, in which the participants had to freely recall as many of the list items as possible; there were no retrieval cues, and there was no previous retrieval practice.

Procedure. Each participant was presented all 16 DRM lists, 4 lists in each of the four experimental conditions. The order of lists was determined by blocked randomization. Each block of lists contained 1 list from each of the four experimental conditions, resulting in four blocks with 4 lists each. The ordering of lists within each block was determined randomly, except that throughout the series of lists, no 2 lists from the same experimental condition appeared in sequence. The assignment of the single lists to the four experimental conditions was balanced across participants, so that each list served equally often in each of the four experimental conditions. In addition, across participants, mean position of each single list was the same in each of the four experimental conditions.

Presentation. The items of a list were presented successively and in random order. Each item was displayed on a computer screen for $1.5 \mathrm{sec}$. In the part-list cuing, the retrieval practice, and the control conditions, the critical item was part of the presented item list. In these cases, the restriction was imposed that the critical item was never presented in the first three or last three positions of a list. In the false-memory condition, the critical item was not part of the presented list. After the presentation of a list, there was a 1-min distractor task, in which four-digit numbers appeared one at a time for $2 \mathrm{sec}$ each and the participants read the four digits aloud in ascending order of value.

Test. In the retrieval practice condition, the participants were then given a two-page test booklet. On the first page, the word stems of the seven practice items were provided, and the participants were given $40 \mathrm{sec}$ to write down the previously presented items that corresponded to the cues. The order of the word stems was identical to the items' order in the Stadler et al. (1999) norms. This practice phase was promptly followed by a free-recall test. The participants were instructed to turn the page and were presented an empty sheet of paper. They were instructed to write down as many of the previously presented list items as possible. They were to recall those items already remembered in the previous test as well. The participants were given 2 min for this task. In the part-list cuing condition, the participants were presented a single sheet of paper with the seven cue items printed on the top. The order of the cue items again corresponded to the items' order in the Stadler et al. norms. The participants were instructed to read these items aloud and then were given 2 min to write down, on the same sheet of paper, as many of the remaining list items as possible. In the false-memory and the control conditions, finally, there was no retrieval practice and no presentation of cue items. The participants were engaged in a free-recall test and had 2 min to write down, on a single sheet of paper, as many of the list items as possible. After presentation and test of each single list, there was a short break of $1 \mathrm{~min}$, during which the participants were engaged in conversation. After 8 of the 16 lists, there was a longer break of $5 \mathrm{~min}$.

\section{Results}

Effects of part-list cuing and retrieval practice. We examined the effects of part-list cuing and retrieval practice on recall of the critical and noncritical items ${ }^{1}$ (see Table 1). The noncritical items showed the expected pattern. Recall performance went down from $63.9 \%$ in the control condition to $58.5 \%$ in the part-list cuing condition and $55.6 \%$ in the retrieval practice condition. This effect of recall condition was statistically reliable $[F(2,110)=8.9$, $\left.M S_{\mathrm{e}}=0.011, p<.001\right]$. Similarly, recall performance for the critical items went down from $88.8 \%$ in the control con- 
dition to $72.8 \%$ in the part-list cuing condition and $74.5 \%$ in the retrieval practice condition. Again, this reduction in recall performance reached significance $[F(2,110)=13.2$, $\left.M S_{\mathrm{e}}=0.033, p<.001\right]$. The effects of part-list cuing and retrieval practice on item recall did not differ reliably, for either the noncritical items $\left[F(1,55)=2.4, M S_{\mathrm{e}}=0.009\right.$, $p>.10]$ or the critical ones $[F(1,55)<1]$.

Inspection of Table 1 suggests that the effects of retrieval practice and part-list cuing were larger for the critical items than for the noncritical ones. Indeed, part-list cuing induced $5.4 \%$ forgetting for the noncritical items but $16.0 \%$ for the critical ones; similarly, retrieval practice induced $8.2 \%$ forgetting for the noncritical items but $14.3 \%$ for the critical ones. A $2 \times 3$ analysis of variance (ANOVA) with the two factors of item type (noncritical or critical) and recall condition (control, cuing, or retrieval) confirmed that critical and noncritical items differed in amount of forgetting. The results showed a significant main effect of item type $\left[F(1,55)=138.3, M S_{\mathrm{e}}=0.023, p<.001\right]$, a significant main effect of recall condition $\left[F(2,110)=23.6, M S_{\mathrm{e}}=\right.$ $0.019, p<.001]$, and a significant interaction between the two factors $\left[F(2,110)=3.2, M S_{\mathrm{e}}=0.025, p<.05\right]$.

False-recall levels. In agreement with the results from previous studies (McDermott, 1997; Miller \& Wolford, 1999), there was a clear-cut difference in recall of the critical items, depending on whether these items were part of the presented item list or not: $88.8 \%$ of the critical items were (veridically) recalled in the control condition (i.e., when they were part of the presented item list), and $37.1 \%$ of the items were (falsely) recalled in the false-memory condition (i.e., when they were not part of the presented item list) $\left[F(1,55)=165.8, M S_{\mathrm{e}}=0.045, p<.001\right]$. As was expected, there was no difference in recall performance between the two conditions with respect to noncritical item recall. In the control condition, $63.9 \%$ of these items were recalled; in the false-memory condition, $65.8 \%$ of the items were recalled $\left[F(1,55)=1.1, M S_{\mathrm{e}}=0.009, p=.30\right]$.

Prior work has shown that false-recall levels can vary drastically across item lists (McEvoy et al., 1999; Roediger et al., 2001; Stadler et al., 1999). This holds true for the present study as well: False-recall levels varied from $7.1 \%$ (anger) up to $71.4 \%$ (window). We used false-recall levels of the critical items in the false-memory condition to construct two sets of item lists. Set 1 consisted of the eight DRM lists with the highest false-recall levels (high falserecall set: mean, 53\%; minimum, 43\%; maximum, 71\%); Set 2 consisted of the eight DRM lists with the lowest false-recall levels (low false-recall set: mean, 20\%; minimum, $7 \%$; maximum, 36\%). Mean false-recall level differed significantly between the two sets of lists $[F(1,47)=$ $\left.27.4, M S_{\mathrm{e}}=0.090, p<.001\right] .^{2}$

High false-recall level versus low false-recall level lists. Recall performance of the noncritical items did not differ reliably across the two sets of lists. In the control condition, recall of the noncritical items was $64.1 \%$ in the high false-recall set of lists and $63.3 \%$ in the low false-recall set; in the part-list cuing condition, $57.1 \%$ of the items were recalled in the high false-recall set and $61.1 \%$ in the low false-recall set; in the retrieval practice condition, $56.1 \%$ of the items were recalled in the high false-recall set and $57.0 \%$ in the low false-recall set. In none of the three recall conditions was the difference in recall performance across the two sets of lists reliable (all $p \mathrm{~s}>.15$ ). These findings were confirmed through the results of a $3 \times 2$ ANOVA with the two factors of recall condition (control, cuing, or retrieval) and list set (high false recall or low false recall), in which the effects of recall condition and list set were analyzed simultaneously. Although the analyses again showed a significant main effect of recall condition $[F(2,78)=4$. , $\left.M S_{\mathrm{e}}=0.103, p<.02\right]$, there was no significant main effect of list set $\left[F(1,39)=2.8, M S_{\mathrm{e}}=0.044, p>.10\right]$ and no significant interaction between the two factors $[F(2,78)<1]$.

As opposed to noncritical item recall, recall performance of the critical items did vary across the two sets of lists. Whereas recall performance was still about the same in the control condition-recall was $88.6 \%$ in the high false-recall set of lists and $86.2 \%$ in the low false-recall set $\left[F(1,47)=1.7, M S_{\mathrm{e}}=0.010, p>.65\right]$ - the two sets of lists differed largely in the extent to which they showed effects of part-list cuing and retrieval practice (see Table 1). We found only a slight effect of recall condition for the high false-recall set of lists: Recall varied from $88.6 \%$ in the control condition to $81.4 \%$ in the part-list cuing condition and $87.2 \%$ in the retrieval practice condition. This slight variation across recall conditions did not reach statistical significance $[F(2,86)<1]$. There was a clear-cut effect of recall condition for the low false-recall set of lists, however: Recall declined from $86.2 \%$ in the control condition to $67.0 \%$ in the part-list cuing condition and $65.5 \%$ in the retrieval practice condition. This decline in performance reached statistical significance $\left[F(2,86)=7.2, M S_{\mathrm{e}}=0.063\right.$, $p<.001]$.

The results of a $2 \times 3$ ANOVA with the two factors of list set (high false recall or low false recall) and recall condition (control, cuing, or retrieval) confirmed the conclusion that critical item recall in the part-list cuing and retrieval practice conditions was lower in the low false-recall than the high false-recall set of lists. We found a significant main effect of set $\left[F(1,39)=15.1, M S_{\mathrm{e}}=0.080, p<.001\right]$, a significant main effect of recall condition $[F(2,39)=6.2$, $\left.M S_{\mathrm{e}}=0.080, p=.002\right]$, and a significant interaction between the two factors $\left[F(2,39)=2.6, M S_{\mathrm{e}}=0.068, p<\right.$ $.05]$. The effects of part-list cuing and retrieval practice on recall performance did not differ in either the high falserecall or the low false-recall set of lists $[F(1,39)<1]$.

Success of retrieval practice and effect on practiced items. As is indicated from the observed recall impairment for the nonpracticed items in the retrieval practice condition, retrieval of the to-be-practiced items in the retrieval practice phase was successful. On average, $89.7 \%$ of these items were recalled. As previous studies have shown, retrieval practice not only impairs later recall of nonpracticed items, but also, at the same time, improves later recall of the practiced items. This pattern was also present 
in our data. We compared performance of the practiced items in the retrieval practice condition with performance of the same items in the control condition: Recall in the retrieval practice condition was $81.4 \%$, whereas recall in the control condition was only $63.7 \%\left[F(1,55)=83.2, M S_{\mathrm{e}}=\right.$ $0.010, p<.001]$.

\section{Discussion}

Three major results arise from Experiment 1. First, retrieval practice and part-list cuing on a subset of the noncritical items not only impaired recall of the remaining noncritical lists in DRM lists, but also impaired recall of the critical items. Second, there is a relation between the susceptibility of the critical items to the effects of retrieval practice and part-list cuing and these items' level of false recall: Low false-recall levels are accompanied by large effects of retrieval practice and part-list cuing, whereas high false-recall levels are accompanied by hardly any effects of retrieval practice and part-list cuing. Third, part-list cuing and retrieval practice induce roughly the same effects on recall performance, qualitatively and quantitatively. This holds for both the noncritical and the critical items and, for the critical items, for both high false-recall level and low false-recall level lists.

The results of previous studies on the role of integration in retrieval-induced forgetting have shown that strong interconnections between practiced and nonpracticed items greatly reduce or eliminate forgetting (Anderson \& Bell, 2001; Anderson, Green, \& McCulloch, 2000; Anderson \& McCulloch, 1999; Bäuml \& Hartinger, 2002). Such an effect of integration was present in our data as well. Indeed, the critical items showed considerable retrieval-induced forgetting in DRM lists with low false-recall levels but showed hardly any forgetting in DRM lists with high falserecall levels. Because high false-recall levels indicate a relatively high degree of interconnections between a list's critical item and its noncritical items and low false-recall levels indicate a relatively low degree (Roediger et al., 2001), the relation between level of false recall and amount of retrieval-induced forgetting replicates the forgettingreducing effect of a high degree of integration between practiced and nonpracticed items.

At the core of Experiment 1 was the question of whether integration affects part-list cuing in the same manner as retrieval-induced forgetting. As it turned out, the effects of part-list cuing were analogous to those of retrieval practice, both in pattern and in size. Indeed, the critical items showed considerable part-list cuing in DRM lists with low false-recall levels but showed hardly any forgetting in DRM lists with high false-recall levels. This result is inconsistent with the strategy disruption view of part-list cuing (D. R. Basden \& B. H. Basden, 1995; Sloman et al., 1991). High false-recall lists reflect a higher degree of interconnections between the noncritical items and the critical ones than do low false-recall lists. Thus, they should show a higher degree of organization and, therefore, be more vulnerable to effects of part-list cuing than are low false-recall lists. However, just the opposite result arose, with more part-list cuing in low than in high false-recall lists.

The parallel effect of integration in retrieval-induced forgetting and part-list cuing suggests that the two forms of forgetting are mediated by similar mechanisms. In particular, this parallel is consistent with the view that not only retrieval-induced forgetting, but also part-list cuing is caused by inhibition. According to the inhibition account, the detrimental effects of part-list cuing result because cue items may be retrieved before noncue items, either overtly or covertly, thus causing retrieval-induced inhibition of the noncue items (Anderson et al., 1994). If the detrimental effects of retrieval and cuing are due to the same mechanism, retrieval-induced forgetting and part-list cuing should show many further parallels. In Experiment 2, we examined such a further possible parallel between the two forms of forgetting.

\section{EXPERIMENT 2}

Whereas in Experiment 1, we focused on critical items' veridical recall, in Experiment 2 we focused on critical items' false recall. We investigated whether part-list cuing and retrieval practice have the same or a different influence on critical items' false recall. In two very recent studies, how part-list cuing affects false recall has already been examined (Kimball \& Bjork, 2002; Reysen \& Nairne, 2002). In both studies, a number of DRM lists were presented to participants. The critical items were not part of the studied lists. At test, a subset of the noncritical items was provided as a retrieval cue. Consistent with the results of the present Experiment 1, this part-list cuing impaired recall of the remaining noncritical items, relative to a control condition in which no cue items were provided. More important, the cuing also reduced recall levels of the nonstudied critical items, thus indicating that part-list cuing reduces false recall as well.

We argued in Experiment 1 that the cuing-induced reduction in veridical recall is caused by inhibitory processes. However, the reduction in false recall might be the result of inhibition as well. If false recall of the nonstudied critical items reflects activation of these items during study (Collins \& Loftus, 1975; Roediger et al., 2001; see also Kimball \& Bjork, 2002, and Reysen \& Nairne, 2002), both the noncritical items and the nonstudied critical ones should be active during cuing and should compete for conscious recall. Following the inhibition view, the presentation of the noncritical items as retrieval cues then might lead to covert retrieval of these items, causing retrieval-induced inhibition of the nonstudied critical items and, thus, reducing false recall.

If part-list cuing reduces false recall and this reduction is caused by inhibition, false recall should be reduced by retrieval practice as well. In fact, not only covert retrieval of a subset of the noncritical items should induce inhibition of the nonstudied critical items, but also overt retrieval of these items should cause inhibition. Therefore, if both the critical items and the noncritical ones were active during re- 
trieval practice, the not-to-be-retrieved critical items should be inhibited, and false-recall levels should decrease. This prediction was examined in Experiment 2.

As in Experiment 1, the participants studied DRM lists. In contrast to Experiment 1, however, in Experiment 2 the critical items were not part of the studied lists, thus addressing these items' false recall. The participants again recalled the lists under three different conditions: (1) a freerecall condition, which served as the control condition, (2) a part-list cuing condition, in which a subset of the noncritical items was provided as a retrieval cue at test, and (3) a retrieval practice condition, in which retrieval of a subset of the noncritical items was practiced before there was a free recall of all list items. We examined how retrieval practice influences false-recall rates and whether the effect of retrieval practice is the same as or different from the effect of part-list cuing.

\section{Method}

Participants. Sixty-six psychology students at the University of Regensburg participated in the experiment. They were tested individually.

Materials. Fifteen of the 16 DRM lists employed in Experiment 1 were also used in Experiment 2. The list with the lowest observed false-recall level (anger) was eliminated. The same 14 items from each list were used as those in Experiment 1.

Design and Procedure. The participants studied DRM lists consisting of 14 items each. The critical items were not part of the studied lists. There were three experimental conditions, which differed in recall conditions only. Following Experiment 1, there was a partlist cuing condition, a retrieval practice condition, and a control condition. Each of the three conditions was identical to the corresponding condition used in Experiment 1.

Each participant was presented all 15 DRM lists, 5 lists in each of the three experimental conditions. The ordering of lists was analogous to that in Experiment 1 and again was determined by blocked randomization. Each list served equally often in each of the three experimental conditions. Mean position of each single list was the same in each of the three experimental conditions. Presentation and test of the single lists were identical to those in Experiment 1, with the only exception that the critical items were never part of the studied lists.

\section{Results}

Effects of part-list cuing and retrieval practice. The noncritical items showed the same recall pattern as that in Experiment 1 (see Table 1). Recall performance went down from $59.7 \%$ in the control condition to $53.4 \%$ in the partlist cuing condition and $50.3 \%$ in the retrieval practice condition. This effect of recall condition was statistically reliable $\left[F(2,130)=22.2, M S_{\mathrm{e}}=0.007, p<.001\right]$. Once again, the critical items showed forgetting as well. Recall performance for the critical items went down from $35.8 \%$ in the control condition to $23.3 \%$ in the part-list cuing condition and $27.9 \%$ in the retrieval practice condition. This reduction in recall performance reached significance $\left[F(2,130)=6.7, M S_{\mathrm{e}}=0.039, p=.002\right]$. As in Experiment 1 , the effects of part-list cuing and retrieval practice on item recall did not differ reliably, for either the noncritical items $\left[F(1,65)=3.8, M S_{\mathrm{e}}=0.008, p>.05\right]$ or the critical ones $\left[F(1,65)=1.8, M S_{\mathrm{e}}=0.037, p>.15\right]$.
The effect of retrieval practice was roughly the same for the critical and the noncritical items ( $7.9 \%$ vs. $9.6 \%)$, but there was a slightly larger effect of part-list cuing on the critical than on the noncritical items $(12.5 \%$ vs. $6.4 \%)$. Statistical analyses revealed, however, that the effect of recall condition did not vary reliably with item type. The results from a $2 \times 3$ ANOVA with the two factors of item type (noncritical or critical) and recall condition (control, cuing, or retrieval) showed a significant main effect of item type $\left[F(1,65)=88.4, M S_{\mathrm{e}}=0.073, p<.001\right]$ and a significant main effect of recall condition $[F(2,130)=16.3$, $\left.M S_{\mathrm{e}}=0.022, p<.001\right]$ but no significant interaction between the two factors $\left[F(2,130)=2.3, M S_{\mathrm{e}}=0.024, p>.10\right]$.

High false-recall level versus low false-recall level lists. Analogous to Experiment 1, we used false-recall levels of the critical items in the control condition to construct two sets of lists. Set 1 consisted of the eight DRM lists with the highest false-recall levels (high false-recall set: mean, $50 \%$; minimum, 36\%; maximum, 68\%); Set 2 consisted of the seven DRM lists with the lowest false-recall levels (low false-recall set: mean, 20\%; minimum, 9\%; maximum, $32 \%) .{ }^{3}$ Mean false-recall levels differed significantly between the two sets of lists $\left[F(1,65)=31.8, M S_{\mathrm{e}}=0.092, p<\right.$ $.001]$.

Unlike in Experiment 1, we found a clear effect of recall condition for the high false-recall set of lists: Recall decreased from $49.9 \%$ in the control condition to $31.3 \%$ in the part-list cuing condition and $35.6 \%$ in the retrieval practice condition. This variation across recall conditions reached significance $\left[F(2,130)=7.6, M S_{\mathrm{e}}=0.082, p=\right.$ $.001]$. There was no reliable difference between the effects of cuing and retrieval practice, however $[F(1,65)<1]$. As in Experiment 1, recall levels for many of the low false-recall lists were very low (see notes 2 and 3 ). As a result, for these lists, not much room was left to show substantial forgetting. It is not surprising, therefore, that we found only a slight effect of recall condition for this set of lists. In fact, recall varied from $20.2 \%$ in the control condition to $15.9 \%$ in the part-list cuing condition and $19.6 \%$ in the retrieval practice condition. This decline in performance did not reach significance $[F(2,130)<1]$, a finding presumably reflecting a floor effect. Again, there was no reliable difference between the effects of cuing and retrieval practice $[F(1,65)<1]$.

Despite the tendency for larger effects of cuing and retrieval practice in high false-recall than in low false-recall lists, the results of a $2 \times 3$ ANOVA with the two factors of list set (high false recall or low false recall) and recall condition (control, cuing, or retrieval) suggested that amount of forgetting was roughly comparable in high false-recall and low false-recall lists. In fact, they showed a significant main effect of set $\left[F(1,65)=42.3, M S_{\mathrm{e}}=0.099, p<.001\right]$ and a significant main effect of recall condition $[F(2,130)=$ $\left.4.1, M S_{\mathrm{e}}=0.096, p<.02\right]$ but no significant interaction between the two factors $\left[F(2,130)=2.9, M S_{\mathrm{e}}=0.073, p>.05\right]$. Due to the supposed floor effects for low false-recall lists, however, no sound conclusions can be drawn from the interaction analysis. 
Success of retrieval practice and effect on practiced items. Retrieval of the to-be-practiced items in the retrieval practice phase was again successful. On average, $84.3 \%$ of the items were recalled. This retrieval practice improved recall of the practiced items at test. We found $81.3 \%$ recalled items in the retrieval practice condition and 59.8\% recalled items in the control condition $[F(1,65)=246.7$, $\left.M S_{\mathrm{e}}=0.006, p<.001\right]$.

\section{Discussion}

Part-list cuing with a subset of the noncritical items impaired recall of the remaining studied items, thus replicating corresponding results from Experiment 1. More important, part-list cuing impaired recall of the nonstudied critical items as well. This finding extends the results from Experiment 1 for critical items' veridical recall to critical items' false recall. It is consistent with the results from very recent work, in which part-list cuing was also found to reduce false recall (Kimball \& Bjork, 2002; Reysen \& Nairne, 2002).

Similar to part-list cuing, retrieval practice on a subset of the noncritical items impaired recall of the remaining noncritical items and recall of the nonstudied critical items. Together with the results from Experiment 1, this finding indicates that retrieval practice on noncritical items reduces both critical items' veridical recall and their false recall. This finding agrees with the results from very recent work by Starns and Hicks (in press). Parallel to our study, Starns and Hicks examined false recognition and false recall in DRM lists. Retrieval practice consistently reduced false-memory performance.

At the core of Experiment 2 was the question of whether retrieval practice and part-list cuing influence false memories in the same manner. The results showed substantial reductions in false recall as a result of both retrieval practice and part-list cuing. Moreover, the amount of "forgetting" was largely the same for the two types of manipulations, indicating that the parallels between part-list cuing and retrieval practice are not only qualitative, but also quantitative in nature. Once again, these results are consistent with retrieval-induced forgetting and part-list cuing's being mediated by similar mechanisms. They are consistent with the hypothesis that false recall reflects activation during study and that both noncritical items' overt retrieval, as caused by retrieval practice, and their covert retrieval, as caused by part-list cuing, lead to inhibition of the nonstudied critical items. This fits with the view adopted in Experiment 1 that not only retrieval-induced forgetting, but also part-list cuing is caused by inhibitory processes.

In Experiment 1, the critical items were part of the studied lists. This physical presence of the critical items induced an integration effect. In fact, retrieval-induced forgetting and part-list cuing were effectively eliminated for critical items in high false-recall lists. Such an integration effect was not present in Experiment 2, in which the critical items were not part of the studied lists. In this case, the critical items showed quite normal amounts of retrievalinduced forgetting and part-list cuing. This finding supports the suggestion mentioned in Experiment 1 that the physical presence of the critical items in DRM lists may enhance their degree of connectedness to the noncritical items, thus leading to a higher degree of integration and a reduction in the amount of forgetting. Our results, therefore, add to the list of dissociations between veridical and false recall (e.g., McDermott, 1996, McDermott \& Watson, 2001). Only veridical recall, but not false recall, shows integration effects.

\section{GENERAL DISCUSSION}

We investigated retrieval-induced forgetting and partlist cuing in DRM lists, with regard to noncritical and critical item recall and with regard to veridical and false recall. A quite simple picture arose: Both retrieval practice and part-list cuing induced forgetting of noncritical and critical items' veridical recall (Experiment 1), showed an integration effect in high false-recall lists (Experiment 1), and reduced not only critical items' veridical recall, but their false recall as well (Experiment 2). All of these parallels between retrieval practice and part-list cuing held both in pattern and in size.

The parallels between retrieval practice and part-list cuing found in Experiments 1 and 2 are consistent with the results from a number of recent studies. Bäuml et al. (2002), for instance, let participants study categorized lists, with each category consisting of either strong and moderate or weak and moderate items. Presenting the moderate items as retrieval cues at test impaired recall of the strong items but had no detrimental effect on recall of the weak ones. A corresponding effect of item strength was found in retrievalinduced forgetting as well (Anderson et al., 1994; Bäuml, 1998; but see Butler et al., 2001). Hicks and Starns (in press) demonstrated that retrieval-induced forgetting occurs not only in recall, but also in recognition, a result that mimics a similar finding in part-list cuing (Todres \& Watkins, 1981). Furthermore, it was shown that not only the presentation of semantically related extralist items as retrieval cues (Roediger et al., 1977; Watkins, 1975), but also the generation of such extralist items (Bäuml, 2002) can cause forgetting of previously learned material.

The parallel effects of cuing and retrieval found in the present and prior work indicate that part-list cuing and retrieval-induced forgetting are mediated by similar mechanisms. In particular, they are consistent with the view that not only retrieval-induced forgetting, but also part-list cuing is caused by inhibitory mechanisms. Following this line of reasoning, retrieval causes forgetting of related material through overt retrieval of the to-be-practiced material, whereas cuing causes forgetting through mostly covert retrieval of the cue material (Anderson et al., 1994). In fact, this inhibition view can account for both the present results and those reported in recent work. On the basis of the proposal of a general inhibitory deficit in older adults (Hasher $\&$ Zacks, 1988), it is also consistent with the finding that younger, but not older, adults have been found to show detrimental effects of part-list cuing (Foos \& Clark, 2000).

In the literature, part-list cuing has often been explained in terms of strategy disruption or competition. Strategy 
disruption assumes that cuing induces a change in the retrieval process from a more effective one when cues are absent to a less effective one when they are present (D. R. Basden \& B. H. Basden, 1995; Sloman et al., 1991). The results of the present two experiments cast doubt on this proposal. Whereas strategy disruption predicts that integration increases the detrimental effects of cuing, the results of Experiment 1 indicate that integration reduces, or even eliminates, the effect. Furthermore, by showing that part-list cuing and retrieval practice induce not only the same qualitative, but also the same quantitative effects on recall performance (veridical and false recall), our results provide an additional challenge for the disruption account.

The competition principle assumes that part-list cuing creates a competition disadvantage for the noncue items (Rundus, 1973). This principle was favored by Kimball and Bjork (2002) in explaining the effect of part-list cuing on false recall. The competition explanation, however, suffers from two disadvantages. One disadvantage is that the principle has been found to be inadequate to account for retrieval-induced forgetting (Anderson et al., 1994; Anderson \& Spellman, 1995). Therefore, despite the strong similarities between part-list cuing and retrieval-induced forgetting, quite different mechanisms would have to be assumed to account for the two forms of forgetting. The other disadvantage is that the competition principle has problems in explaining part-list cuing in veridical recall. The finding that high-frequency exemplars of categories show more part-list cuing than do low-frequency exemplars (Bäuml et al., 2002), for instance, is inconsistent with the principle. However, it agrees with inhibition.

One of the goals of the present study was to compare the effect of part-list cuing as directly as possible with the effect of retrieval practice. In part-list cuing, there is typically no delay or distractor task between cuing and test, and there is also no control of output interference at test. Therefore, in the present experiments, we examined the effect of retrieval practice without controlling for possible recency effects and without controlling for possible effects of output interference at test. In addition, we used just one retrieval practice trial to induce retrieval-inducedforgetting. Trimming the retrieval manipulationin this manner should not have changed the way in which retrieval practice causes forgetting.

Indeed, recent experiments on retrieval-induced forgetting have varied in whether they controlled for output interference effects at test (Anderson et al., 1994; Bäuml \& Hartinger, 2002) or not (Anderson et al., 1994; R. E. Smith \& Hunt, 2000); the basic effect remained the same. Bäuml and Aslan (in press) directly compared the effect of recency control and delay between learning and test on retrieval-induced forgetting; the results were not affected. Retrieval practice effects on false recall were examined with recency control (Starns \& Hicks, in press) and without recency control (Experiment 2); the forgetting was comparable. And finally, evidence was found that three retrieval practice trials do not induce more forgetting than does a single retrieval practice trial (Macrae \& MacLeod, 1999). All of these findings indicate that the effects of part-list cuing and retrieval practice can be compared rather directly, thus allowing qualitative and quantitative comparisons between the two forms of forgetting.

In conclusion, our results demonstrate that retrieval practice and part-list cuing influence veridical and false recall in DRM lists in the same manner, both in pattern and in size. This result challenges accounts of retrievalinduced forgetting and part-list cuing that are based on largely different mechanisms and, rather, suggests that quite similar mechanisms mediate the two forms of forgetting. Following the inhibition view of retrieval-induced forgetting, the findings suggest that not only the detrimental effects of retrieval, but also the detrimental effects of cuing are caused by inhibitory processes. At the very least, this account provides the most parsimonious explanation of the present results and those from recent work.

\section{REFERENCES}

Anderson, M. C., \& Bell, T. (2001). Forgetting our facts: The role of inhibitory processes in the loss of propositional knowledge. Journal of Experimental Psychology: General, 130, 544-570.

Anderson, M. C., Bjork, E. L., \& Bjork, R. A. (2000). Retrievalinduced forgetting: Evidence for a recall-specific mechanism. Psychonomic Bulletin \& Review, 7, 522-530.

Anderson, M. C., BJork, R. A., \& BJork, E. L. (1994). Remembering can cause forgetting: Retrieval dynamics in long-term memory. Journal of Experimental Psychology: Learning, Memory, \& Cognition, 20, 1063-1087.

Anderson, M. C., Green, C., \& McCulloch, K. C. (2000). Similarity and inhibition in long-term memory: Evidence for a two-factor theory. Journal of Experimental Psychology: Learning, Memory, \& Cognition, 26, 1141-1159.

Anderson, M. C., \& McCulloch, K. C. (1999). Integration as a general boundary condition on retrieval-induced forgetting. Journal of Experimental Psychology: Learning, Memory, \& Cognition, 25, 608629.

Anderson, M. C., \& Spellman, B. A. (1995). On the status of inhibitory mechanisms in cognition: Memory retrieval as a model case. Psychological Review, 102, 68-100.

Basden, B. H., Basden, D. R., \& Stephens, J. P. (2002). Part-set cuing of order information in recall tests. Journal of Memory \& Language, 47, 517-529.

BASDEN, D. R. (1973). Cued and uncued recall of unrelated words following interpolated learning. Journal of Experimental Psychology, 98, 429-431.

BASDEN, D. R., \& BASDEN, B. H. (1995). Some tests of the strategy disruption hypothesis of part-list cuing inhibition. Journal of Experimental Psychology: Learning, Memory, \& Cognition, 21, 1656-1669.

Basden, D. R., Basden, B. H., \& Galloway, B. C. (1977). Inhibition with part-list cuing. Journal of Experimental Psychology: Human Learning \& Memory, 3, 100-108.

BäumL, K.-H. (1997). The list-strength effect: Strength-dependent competition or suppression? Psychonomic Bulletin \& Review, 4, 260-264.

BäUML, K.-H. (1998). Strong items get suppressed, weak items do not: The role of item strength in output interference. Psychonomic Bulletin \& Review, 5, 459-463.

BäUmL, K.-H. (2002). Semantic generation can cause episodic forgetting. Psychological Science, 13, 357-361.

BäUmL, K.-H., \& Aslan, A. (in press). Part-list cuing as instructed retrieval inhibition. Memory \& Cognition.

BäUmL, K.-H., \& HARTINGER, A. (2002). On the role of item similarity in retrieval-induced forgetting. Memory, 10, 215-224.

BäUML, K.-H., KISSLER, J., \& RAK, A. (2002). Part-list cuing in amnesic patients: Evidence for a retrieval deficit. Memory \& Cognition, 30, 862-870.

Butler, K. M., Williams, C. C., Maki, R. H., \& Zacks, R. T. (2001). 
A limit on retrieval-induced forgetting. Journal of Experimental Psychology: Learning, Memory, \& Cognition, 27, 1314-1319.

Ciranni, M. A., \& Shimamura, A. P. (1999). Retrieval-induced forgetting in episodic memory. Journal of Experimental Psychology: Learning, Memory, \& Cognition, 25, 1403-1414.

Collins, A. M., \& Loftus, E. F. (1975). A spreading activation theory of semantic memory. Psychological Review, 82, 407-428.

DEESE, J. (1959). On the prediction of occurrence of particular verbal intrusions in immediate recall. Journal of Experimental Psychology, 58, 17-22.

Foos, P. W., \& Clark, M. C. (2000). Old age, inhibition, and the part-set cuing effect. Educational Gerontology, 26, 155-160.

Geiselman, R. E., Fisher, R. P., MacKinnon, D. P., \& Holland, H. L. (1985). Eyewitness memory enhancement in the police interview: Cognitive retrieval mnemonics versus hypnosis. Journal of Applied Psychology, 70, 401-412.

HASHER, L., \& ZACKS, R. T. (1988). Working memory, comprehension, and aging: A review and a new view. In G. H. Bower (Ed.), The psychology oflearning andmotivation (Vol. 22, pp. 193-225). San Diego: Academic Press.

Hicks, J. L., \& Starns, J. J. (in press). Retrieval-induced forgetting occurs in tests of item recognition. Psychonomic Bulletin \& Review.

KIMBALl, D. R, \& BJork, R. A. (2002). Influences of intentional and unintentional forgetting on false memories. Journal of Experimental Psychology: General, 131, 116-130.

LeVy, B. J., \& ANDERson, M. A. (2002). Inhibitory processes and the control of memory retrieval. Trends in Cognitive Sciences, 6, 299-305.

MacLeod, C. M., Dodd, M. D., Sheard, E. D., Wilson, D. E., \& BIBI, U. (2003). In opposition to inhibition. In B. H. Ross (Ed.), The psychology of learning and motivation (Vol. 43, pp. 163-214). San Diego: Academic Press.

Macrae, C. N., \& MacLeod, M. D. (1999). On recollections lost: When practice makes imperfect. Journal of Personality \& Social Psychology, 7, 463-473.

McDermotт, K. B. (1996). The persistence of false memories in list recall. Journal of Memory \& Language, 35, 212-230.

McDermott, K. B. (1997). Priming on perceptual implicit memory tests can be achieved through presentation of associates. Psychonomic Bulletin \& Review, 4, 582-586.

McDermott, K. B., \& Watson, J. M. (2001). The rise and fall of false recall: The impact of presentation duration. Journal of Memory \& Language, 45, 160-176.

McEvoy, C. L., Nelson, D. L., \& Komatsu, T. (1999). What is the connection between true and false memories? The differential role of interitem associations in recall and recognition. Journal of Experimental Psychology: Learning, Memory, \& Cognition, 25, 1177-1194.

Miller, M. B., \& Wolford, G. L. (1999). Theoretical commentary: The role of criterion shift in false memory. Psychological Review, 106, 398-405.

Nickerson, R. S. (1984). Retrieval inhibition from part-set cuing: A persisting enigma in memory research. Memory \& Cognition, 12, 531552.

RaAijmakers, J. G. W., \& Shiffrin, R. M. (1981). Search of associative memory. Psychological Review, 88, 93-134.

Radvansky, G. A. (1999). Memory retrieval and suppression: The inhibition of situation models. Journal of Experimental Psychology: General, 128, 563-579.

READ, J. D. (1996). From a passing thought to a false memory in 2 minutes: Confusing real and illusory events. Psychonomic Bulletin \& Review, 3, 105-111.

Reysen, M. B., \& NAIRne, J. S. (2002). Part-set cuing of false memories. Psychonomic Bulletin \& Review, 9, 389-393.

RoEDIGER, H. L., III (1973). Inhibition in recall from cueing with recall targets. Journal of Verbal Learning \& Verbal Behavior, 12, 644-657.

Roediger, H. L., III, \& McDermott, K. B. (1995). Creating false memories: Remembering words not presented in lists. Journal of Experimental Psychology: Learning, Memory, \& Cognition, 21, 803-814.

Roediger, H. L., III, McDermott, K. B., \& Robinson, K. J. (1998). The role of associative processes in creating false memories. In M. A. Conway, S. E. Gathercole, \& C. Cornoldi (Eds.), Theories of memory II (pp. 187-245). Hove, U.K.: Psychology Press.
Roediger, H. L., III, \& Schmidt, S. R. (1980). Output interference in the recall of categorized and paired associate lists. Journal of Experimental Psychology: Human Learning \& Memory, 6, 91-105.

Roediger, H. L., III, Stellon, C. C., \& Tulving, E. (1977). Inhibition from part-list cues and rate of recall. Journal of Experimental Psychology: Human Learning \& Memory, 3, 174-188.

Roediger, H. L., III, Watson, J. M., McDermott, K. B., \& Gallo, D. A. (2001). Factors that determine false recall: A multiple regression analysis. Psychonomic Bulletin \& Review, 8, 385-407.

Rundus, D. (1973). Negative effects of using list items as recall cues. Journal of Verbal Learning \& Verbal Behavior, 12, 43-50.

Slamecka, N. J. (1968). An examination of trace storage in free recall. Journal of Experimental Psychology, 76, 504-513.

Sloman, S. A., Bower, G. H., \& Rohrer, D. (1991). Congruency effects in part-list cuing. Journal of Experimental Psychology: Learning, Memory, \& Cognition, 17, 974-982.

Sмiт H, A. D. (1971). Output interference and organized recall from long-term memory. Journal of Verbal Learning \& Verbal Behavior, 10, 400-408.

Smith, E. E., Adams, N., \& Schorr, D. (1978). Fact retrieval and the paradox of interference. Cognitive Psychology, 10, 438-464.

Smith, R. E., \& Hunt, R. R. (2000). The influence of distinctive processing on retrieval-induced forgetting. Memory \& Cognition, 28, 503-508.

Stadler, M. A., Roediger, H. L., III, \& McDermott, K. B. (1999). Norms for word lists that create false memories. Memory \& Cognition, 27, 494-500.

StARnS, J. J., \& Hicks, J. L. (in press). Episodic generation can cause semantic forgetting: Retrieval-induced forgetting of false memories. Memory \& Cognition.

Todres, A. K., \& Watkins, M. J. (1981). A part-set cuing effect in recognition memory. Journal of Experimental Psychology: Human Learning \& Memory, 2, 91-99.

Tulving, E. (1974). Cue-dependent forgetting. American Scientist, 62, 74-82.

Tulving, E., \& Pearlstone, Z. (1966). Availability versus accessibility of information in memory for words. Journal of Verbal Learning \& Verbal Behavior, 5, 381-391.

WAT KINS, M. J. (1975). Inhibition in recall with extralist "cues.” Journal of Verbal Learning \& Verbal Behavior, 14, 294-303.

\section{NOTES}

1. Part-list cuing and retrieval practice induce a partition of a list's noncritical items into cue and practiced items, on the one hand, and noncue and nonpracticed items, on the other. Because in the part-list cuing condition the participants had to recall the noncue items only, we restricted analyses to this set of items for all three recall conditions.

2. In Experiment 1, the high false-recall set of lists consisted of the eight lists of window (71\% of false recall), smoke (64\%), cold (64\%), soft $(57 \%)$, slow (50\%), sweet (43\%), sleep (43\%), and smell (43\%). The low false-recall set consisted of the eight lists of river $(36 \%)$, mountain $(36 \%)$, foot $(21 \%)$, doctor $(21 \%)$, cup $(14 \%)$, trash $(14 \%)$, spider $(7 \%)$, and anger $(7 \%)$. When we order our 16 lists according to their falserecall level, this order does not agree perfectly with the order reported in Stadler et al.'s (1999) study. There are at least two possible reasons for the differences. One is that we presented the items visually, whereas Stadler et al. presented the items auditorily. The other reason is that the translation of the items into German made some of the lists less effective and some of the lists more effective in inducing false memories.

3. In Experiment 2, the high false-recall set of lists consisted of the eight lists of soft (68\% of false recall), sweet (50\%), sleep (50\%), window $(50 \%)$, smell (48\%), smoke (43\%), cold (41\%), and slow (36\%). The low false-recall set consisted of the seven lists of trash (32\%), mountain $(27 \%)$, river $(23 \%)$, foot $(23 \%)$, cup $(18 \%)$, spider $(18 \%)$, and doctor $(9 \%)$. The two sets of lists thus were identical to those used in Experiment 1, with the only difference being that, in Experiment 2, the anger list was excluded from study.

(Manuscript received November 15, 2002; revision accepted for publication August 5, 2003.) 